\title{
UNA TRAVESÍA INCONCLUSA: DIVISIONES EN RENOVACIÓN Nacional durante el gobierno de Sebastián Piñera*
}

\author{
An Unconcluded Journey. Divisions within Renovación Nacional \\ During the Administration of Sebastián Piñera
}

\author{
NICOLÁS DÍAZ \\ Pontificia Universidad Católica de Chile
}

\begin{abstract}
RESUMEN
Este trabajo investiga los conflictos al interior de Renovación Nacional (RN) durante la administración de Sebastián Piñera a partir de varias entrevistas a militantes, parlamentarios y dirigentes partidistas. Si bien la prensa y la literatura suelen explicar las diferencias en RN por la existencia de un polo liberal y de uno conservador, sus fracturas actuales siguen una lógica más compleja. Durante la última década constantemente se han actualizado y reconfigurado los conflictos partidarios. Los motivos principales guardan relación con la conducción del partido y su despliegue democrático (verticalistas contra horizontalistas), y con la posición adoptada en función de los enfrentamientos que se han desarrollado entre la mesa directiva y el gobierno (larrainistas contra piñeristas). Estos nuevos ejes de división han significado una reestructuración interna y un reposicionamiento de los caudillos partidistas.
\end{abstract}

Palabras clave: Renovación Nacional, democracia interna, sistema de partidos, Chile, caudillismo

\begin{abstract}
This paper investigates the internal divisions of Renovación Nacional during the Sebastiann Piñera administration through a series of interviews to party members, congressman and party leaders. Even though the press and the literature tends to explain differences within $R N$ due to the existence of a liberal pole and a conservative pole, current fractures follow a more complex logic. During the last decade party conflicts have been restructured around the party leadership and its democratic appeal (verticalists vs. horizontalists), and around the confrontation between the ruling board (mesa directiva) and the government (larrainistas vs. piñeristas). This new cleavages indicate an internal reconfiguration and repositioning of party leaders.
\end{abstract}

Key words: Renovación Nacional, internal democracy, party system, Chile, caudillism

* Esta publicación no hubiese sido posible sin la guía del profesor Juan Pablo Luna. Asimismo, se agradecen profundamente el apoyo y los comentarios de Camila Díaz, Constanza Flores, Josefina Jaureguiberry, Gabriela Lucero y los revisores anónimos. Todo error u omisión es responsabilidad del autor. 


\section{INTRODUCCIÓN}

La victoria presidencial del empresario Sebastián Piñera en 2009 marcó un hito para la derecha chilena -representada por los partidos Renovación Nacional (RN) y Unión Demócrata Independiente (UDI)- al permitirle llegar al gobierno por primera vez desde el retorno de la democracia. Cuatro años después, en las siguientes elecciones, el sector sufriría una de sus peores derrotas en la historia y el partido de Piñera ( $R N)$ entraría en crisis.

En este escenario Andrés Allamand, senador electo, exministro y uno de sus líderes históricos, culpó a Piñera por la extendida derrota política ("Andrés Allamand: 'El principal responsable del fracaso electoral es Piñera'", La Tercera, 2013), lo que fue seguido por la renuncia a RN de varios ministros y parlamentarios. La llamada "ala liberal" del partido se separaría para formar un nuevo movimiento de centro-derecha llamado Amplitud, citando diferencias irreconciliables con la mesa directiva ("Tres diputados renuncian a RN y anuncian nuevo referente: Amplitud", EMOL, 2014).

¿Qué factores desencadenaron un conflicto interno de esas proporciones? ¿Fueron las diferencias de carácter ideológico, o más bien discrepancias coyunturales en torno a los caudillismos del partido? ¿Fue una consecuencia de la derrota electoral o responde a problemas de larga data? ¿Cómo se relaciona la crisis de fines del primer periodo presidencial de la derecha con las anteriores desaveniencias en el partido?

La presente investigación tiene como objetivo discutir los ejes de los conflictos internos de RN durante el cuatrienio de Sebastián Piñera en La Moneda, basados en la revisión de prensa y entrevistas en profundidad a 10 militantes, parlamentarios y autoridades del partido en el periodo de septiembre a diciembre de 2013. Los nombres de los entrevistados se han mantenido anónimos debido a los cargos y la franqueza buscada, pero en el pie de página se especifica la posición y fecha de entrevista en cada una de las citas.

Tradicionalmente, la prensa y la literatura politológica han recurrido a la división conservador-liberal, para entender las múltiples disputas al interior de RN (Mackinnon, 2005; Godoy, 2005; Aleuy y Arriagada, 2001; Arce, 2013). Sin embargo, ciertos análisis (Barozet y Aubry, 2005; Siavelis, 2014) proponen que las diferencias no responden a desacuerdos ideológicos, sino que a faccionalismos inestables ligados a los caudillos y a la coyuntura.

Al respecto, este trabajo cierra la brecha entre ambas posturas. El principal argumento esbozado es que no hay solo un eje de división ideológico ni puramente luchas caudillistas, sino una superposición de conflictos operando en múltiples dimensiones. Durante el gobierno del presidente Piñera se evidenciaron al menos tres niveles de conflicto: uno moralista o normativo (conservadores contra liberales), uno relacionado con la apertura democrática interna del partido (horizontalistas contra verticalistas), y uno caudillista que enfrentó al gobierno con la mesa directiva.

Los estudios a los partidos políticos en Latinoamérica han centrado su atención en el repunte de la izquierda en desmedro de las estrategias de los partidos de derecha (Luna y Kaltwasser, 2011). Dentro del contexto chileno, las peculiaridades organizacionales de la UDI han recibido un alto grado de interés por parte de académicos e investigadores 
(Luna, 2010; Huneeus, 2001; Morales y Burgueño, 2001; Hinojosa, 2009; Klein, 2004; Soto, 2001) mientras que los trabajos enfocados en RN han sido escasos, a pesar de tratarse de uno de los partidos más importantes desde el retorno de la democracia. Este estudio contribuye a subsanar ese vacío académico al ofrecer una perspectiva novedosa desde la mirada que los propios militantes tienen de su institucionalidad, su nivel de democratización interno y las distintas facciones en disputa.

Este trabajo se organiza de la siguiente manera. Al inicio se presenta un breve marco teórico del estudio de la derecha latinoamericana, el caso particular de Renovación Nacional en Chile y la literatura respecto de la organización interna y el faccionalismo de los partidos. Las secciones que siguen demuestran, sobre la base de una revisión de la prensa y entrevistas a militantes, dirigentes y parlamentarios de este conglomerado la existencia de tres niveles de división partidaria durante el gobierno de Sebastián Piñera. En primer lugar, se revisa la evolución de la conocida disputa entre conservadores y liberales. Segundo, se argumenta acerca de cómo el estilo de conducción de sus líderes y su grado de apertura democrática han abierto otro flanco de enfrentamientos y, tercero, se sostiene que la llegada de Sebastián Piñera a La Moneda y la instalación del gobierno gatilló rencillas caudillistas entre la administración entrante y la mesa directiva de la facción. Finalmente, se sugiere cómo este nuevo mapa de disputas internas permite comprender mejor las dinámicas del partido.

\section{MARCO TEÓRICO}

\section{Los partidos políticos y la derecha en América Latina}

A pesar de tener una disminuida influencia en la sociedad y altos niveles de rechazo, los partidos políticos siguen cumpliendo un rol fundamental en las democracias latinoamericanas. Entre sus funciones se encuentran estructurar la competencia política, seleccionar a los candidatos al Parlamento, conducir el gobierno y fiscalizar como oposición (Alcántara, 2004).

Sin embargo, al analizar en mayor detalle su constitución, existe una gran variación institucional tanto en los distintos sistemas de partidos nacionales como entre las agrupaciones de un mismo país. En este sentido, Alcántara propone un continuo que va desde los institucionalizados (que cuentan con una rutinización de sus pautas de comportamiento) hasta las máquinas personalistas-caudillistas (partidos que funcionan basados en un líder carismático, sin vínculos programáticos claros, con una organización irregular y un discurso apolítico).

En cuanto a clasificaciones ideológicas, las etiquetas de izquierda-derecha se han mantenido vigentes en el tiempo para clasificar a los partidos en Latinoamérica tanto por parte de las élites políticas como por los ciudadanos (Alcántara, 2004; Došek, 2011). Luna y Kaltwasser (2014) argumentan a favor de una clasificación que divide a los partidos por su posición frente a la igualdad: los partidos de derecha consideran que las desigualdades entre las personas son naturales y no necesariamente una prioridad del Estado, mientras que los de izquierda buscan reducirlas mediante políticas gubernamentales. 
Luna y Kaltwasser atribuyen el resurgimiento de la izquierda del continente en las últimas décadas (evidenciado en Levitsky y Roberts, 2011), a la dificultad estructural que surge en la derecha al presentar una posición contraria a la igualdad en la región con mayor desigualdad socioeconómica en el mundo.

Roberts (2014), por su parte, argumenta que si bien durante los años noventa la adopción de políticas neoliberales y tecnocráticas, el fin de la Guerra Fría, la adopción de la democracia y el derrumbe de los modelos socialistas significó un escenario favorable y cómodo para la derecha. Sin embargo, en el largo plazo, estos mismos factores sepultarían a la derecha como una minoría constante.

La adopción de la democracia tras el fin de la Guerra Fría abrió espacio para una izquierda democrática que competiría por el poder. Debido a las tremendas inequidades producto de las políticas neoliberales, amplios sectores de la población se vieron atraídos hacia propuestas más estatistas. En este contexto de participación ampliada, la derecha ya no podía recurrir al deslegitimado autoritarismo ni a sus tradicionales prácticas clientelares.

Wiesehoimer y Doyle (2014), quienes analizan el perfil de partidos y electores de acuerdo con varias encuestas en el continente, concuerdan en que existen dificultades estructurales en la derecha para competir con un programa contrario a la redistribución económica. Pero al mismo tiempo, argumentan que si los partidos de ese sector se acercan al centro en cuestiones económicas y ponen el foco en otras dimensiones, tendrán una capacidad real de conectarse con el electorado. De esta forma, temas valóricos (como el rechazo al matrimonio igualitario o al aborto) o cuestiones de seguridad (mano dura contra la delincuencia) podrían ser fundamentales para reencantar a los votantes.

No obstante, Luna y Kaltwasser (2014) subrayan que la derecha en el continente no solo ha abrazado la estrategia de competir por el poder con métodos electorales partidistas. Ha logrado, además, defender sus intereses mediante formas no electorales (mediante el lobby, redes tecnocráticas, acceso desproporcionado a recursos económicos, etc.) o mediante movimientos electorales no partidistas (candidaturas apolíticas personalistas).

Es relevante en este punto recordar a Gibson (1992), quien, en uno de los trabajos seminales respecto de las estrategias políticas conservadoras en Latinoamérica, señala que los partidos de derecha pueden tomar una estrategia segmentada. Esta consiste en distinguir entre sus core constituents (sectores altos que proveen un sustento ideológico y financiero) y sus non-core-constituents (sectores bajos a los cuales se llega por medio de una oferta no ideológica) para generar una base policlasista, a pesar de potenciales intereses divergentes entre las clases. Por esto, la hoja de ruta de la derecha en Latinoamérica está trazada con múltiples caminos potenciales y simultáneos.

\section{La derecha en Chile y Renovación Nacional}

La derecha chilena es un caso excepcional en Latinoamérica por varios motivos. En primer lugar, al estar dentro de uno de los sistemas de partidos multipartidistas más estables del continente (Alcántara, 2004), esta pudo consolidarse y proponer una oferta 
política programática no populista a lo largo de su amplia historia. Si bien el gobierno militar prohibió los partidos políticos, esta facción utilizó sus vínculos con la dictadura para establecerse orgánica y territorialmente (Soto, 2001; Klein, 2004) y constituirse como una fuerza política al regreso de la democracia.

A causa de lo anterior, la derecha chilena es un caso inédito, pues ha decidido competir mediante el desarrollo de una organización partidaria programática. Sin embargo, como señala Siavelis (2014), su posición política ha variado a lo largo del tiempo. En la primera década desde el retorno de la democracia, los partidos de RN y la UDI tuvieron un rol eminentemente reactivo, defendiendo el modelo político y económico heredado del Régimen Militar y actuando como dique de contención ante eventuales esfuerzos reformistas por parte de los gobiernos de la Concertación. El sector estaba en posición de defender sus intereses en gran medida gracias a los llamados enclaves autoritarios de la Constitución (Garretón, 2003). El sistema electoral binominal que premia y empata a las dos primeras mayorías, los altos quórums requeridos para cambios constitucionales, los senadores designados (figura creada para autoridades con derecho a ser senador a base de su cargo y que favorecía mayoritariamente a la derecha), entre otras instituciones, permitían a RN y la UDI bloquear reformas incluso al ser una minoría en el Parlamento.

Aunque los cambios a la Constitución acordados entre las dos grandes coaliciones políticas en 2005 no eliminaron la totalidad de esos enclaves autoritarios (el sistema electoral se mantuvo vigente), sí se empezaron a generar los incentivos para que la derecha adoptara una actitud más proactiva. Desde fines de la década de los noventa, ante el agotamiento de la coalición de centro-izquierda, esta empezó a tomar como banderas de lucha los problemáticos casos de corrupción, la seguridad, el crecimiento económico y la lucha contra el desempleo. Fueron estas consignas las que catapultaron a Sebastián Piñera a la Presidencia de la República como abanderado de RN.

Por su parte, los estudios de la última década pertinentes a este partido lo describen como heterogéneo y descentralizado, con un enfoque estratégico que busca atraer sectores rurales, de clase alta y media alta a diferencia de la UDI y que recibe apoyo de grupos de altos, pero también de muy bajos ingresos (Barozet y Aubry, 2005; Wiesehoimer y Doyle, 2014). A lo largo de los años, las divergencias internas y la falta de un liderazgo unificador han desembocado en intensas pugnas, intermitentes períodos de refundación y la clara segmentación en al menos dos bloques: uno defensor del legado del Régimen Militar y otro de carácter democrático, abierto a cambios progresivos del sistema político (Mackinnon, 2005; Godoy, 2005; Aleuy y Arriagada, 2001).

Sin embargo, al realizar una diferenciación faccionaria en RN únicamente de acuerdo con criterios ideológicos se corre el riesgo de desconocer sus dinámicas internas. Pobres niveles de institucionalización, bajos grados de democracia interna, escasas estrategias de renovación y una gran tendencia al personalismo hacen que la agrupación se configure como una plataforma instrumental, impulsando candidaturas específicas en ausencia de una clara cohesión ideológica (Barozet y Aubry, 2005). Las mismas élites partidarias reconocen como debilidades la precaria institucionalidad, la falta de un mínimo común doctrinario y la baja participación en procesos internos (Luna y Rosenblatt, 2012). 
La estructura actual del partido divide las funciones ejecutivas y representativas en distintos órganos aplicando criterios descentralizadores (Renovación Nacional, n.d.; Figura 1). El principal representante político y mediático es la mesa directiva, electa de forma democrática cada dos años por todos los militantes. El consejo general, por su parte, debe pronunciarse acerca de las principales decisiones del partido y para constituirse toma un modelo que evita la centralización territorial. Cada región, cada distrito y las comunas más importantes eligen democráticamente a una directiva y constituyen un consejo territorial (compuesto a su vez por consejeros electos y otras autoridades del territorio). La cantidad de consejeros por distrito está determinado por la cantidad de votos que el partido obtuvo en la última elección parlamentaria. Estos consejeros electos se desempeñarán simultáneamente como consejeros regionales en su región y como generales en el pleno. En consecuencia, el consejo general tiene representación de todos los distritos pero no de forma equitativa.

Figura 1. Estructura de Renovación Nacional

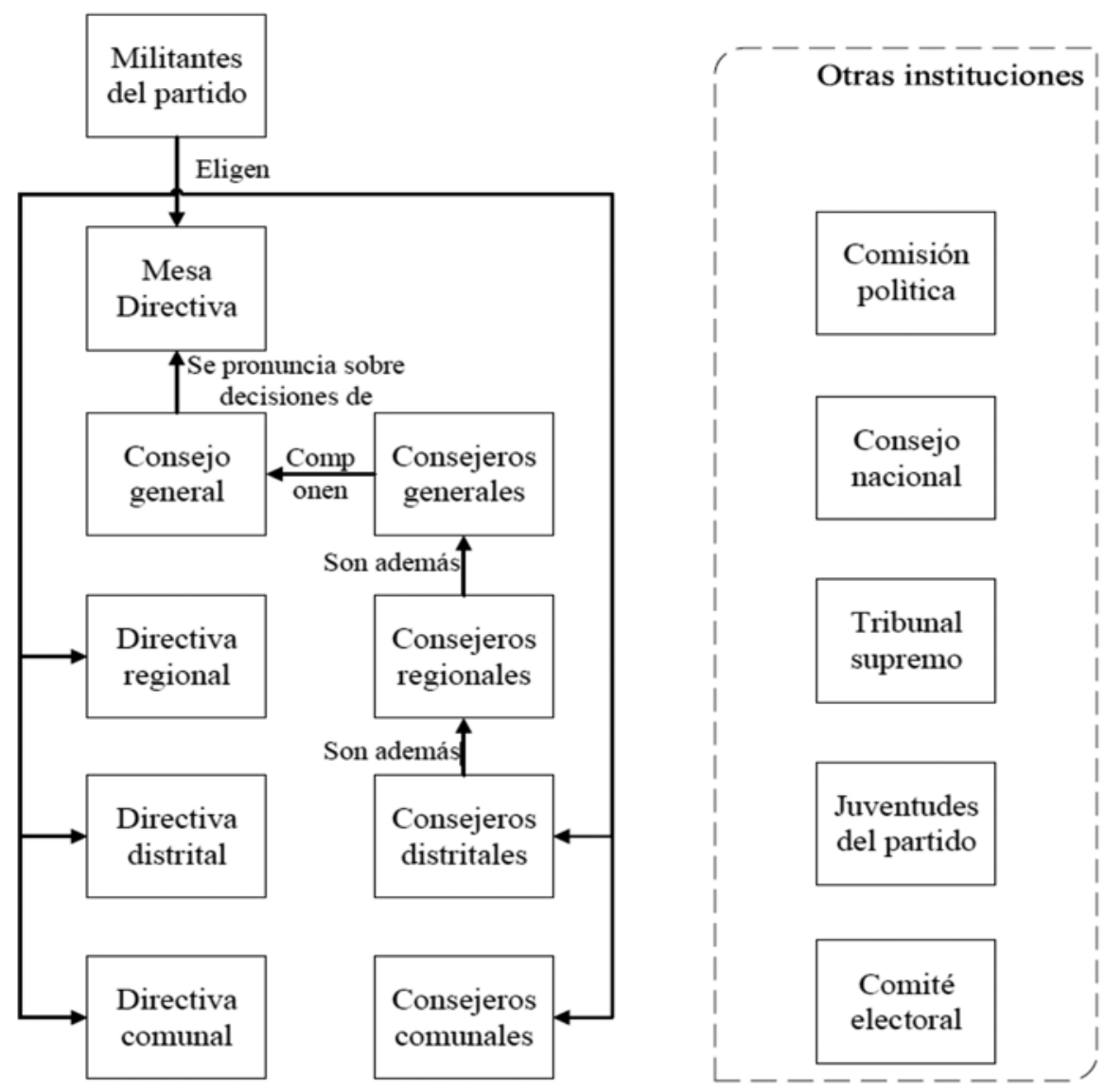

Fuente: Elaboración propia a partir de Renovación Nacional (n.d.). 
Adicionalmente existen algunos organismos que operan de forma paralela. Las juventudes del partido agrupan a los militantes más jóvenes y su directiva es electa por los mismos; el tribunal supremo decide acerca de las faltas de los militantes, recibe acusaciones y defensas frente a reclamos y solicitudes de expulsión; el consejo nacional, que no es comúnmente constituido, actúa de forma paralela al general y versa de cuestiones políticas internas y organizativas. Por su parte, la comisión política es una figura de funcionamiento regular constituida por miembros de la mesa directiva, representantes de los diputados, de los senadores, expresidentes de partido, entre otros, que sesiona constantemente con el objetivo de asesorar a la mesa directiva respecto de la coyuntura política. Por último está el comité electoral, un órgano informal que se constituye a petición de la mesa directiva y que analiza y recomienda posibles candidaturas parlamentarias.

\section{Analizando la organización interna de los partidos}

El estudio de los ejes de división dentro de un partido se relaciona con sus dinámicas internas, institucionalización y grado de apertura democrática. Después de todo, estos no son solo plataformas para impulsar candidaturas o programas, sino que son en sí mismos arenas donde se disputa el poder político.

En su clásico estudio, Ángelo Panebianco (1990) destaca el rol que juegan las coaliciones dominantes a la hora de generar una clasificación de los partidos. El poder de las élites proviene del control de las zonas de incertidumbre (el financiamiento, la comunicación o las reglas formales, entre otros) y la evolución de los conflictos internos permite comprender el grado de organización de los grupos intrapartidarios, ya sea en facciones (en caso de una alta organización) o en tendencias (en caso de que sea baja). Esto determina la dispersión o cohesión de la coalición dominante y el grado de institucionalización del partido. Un alto grado de esta apunta a una coalición dominante cohesionada y a una baja organización de grupos adversos.

Tanto Panebianco como otros académicos que trabajan en la estructura interna de los partidos políticos (Kitschelt, 1994; Levitsky, 2003) se refieren a la dicotomía existente entre flexibilidad y unidad. Un partido unido es más bien monolítico y no da espacio a la disidencia interna, pero al mismo tiempo se torna poco adaptable a presiones internas o externas. Un ejemplo es el caso del Justicialismo en Argentina: un partido sumamente desorganizado, donde el poder de los grupos internos varía en el tiempo, pero que aun así presenta una alta adaptabilidad. Panebianco, a su vez, habla de la necesidad de las élites de entregar legitimidad (la distribución de bienes tangibles o intangibles a sus miembros) y de mantener una estabilidad organizativa que les permita mantenerse en el poder.

En su clasificación de partidos institucionales versus máquinas personalistas en Latinoamérica, Alcántara (2004) asegura en una línea similar que las grandes diferencias entre los partidos del continente radican en cuán concentrado está el poder en su interior. De este modo es posible diferenciarlos de acuerdo con tres puntos: según el control de la selección de candidatos por parte de los líderes nacionales, por la fortaleza de los núcleos de organización de la élite y finalmente, por si cuentan con relaciones de poder 
verticalistas u horizontalistas. Estas tres cuestiones serán discutidas para el caso de RN en las secciones que siguen.

\section{LA EVOLUCIÓN DE LA DISPUTA CONSERVADOR-LIBERAL}

La división entre grupos conservadores y liberales constituye una constante a lo largo de la historia de Renovación Nacional. Como reconoce uno de sus senadores, "Es un partido que abraza las ideas del libre mercado, pero la economía social de mercado, donde hay corrientes liberales y conservadoras".${ }^{1}$ La presencia de un ala liberal enérgica ha sido identificada múltiples veces por la prensa y también reconocida por parlamentarios del mismo partido, aunque siempre como una disidencia a la postura mayoritaria. Figuras como el senador Antonio Horvath o la diputada Karla Rubilar (quienes abandonaron el partido al final del mandato de Piñera) se inscribieron en este grupo y fueron partícipes de importantes polémicas en su trayectoria partidista. Horvath en particular generó un gran revuelo al no apoyar a la candidata oficialista, Evelyn Matthei, en las elecciones presidenciales de 2013. Al ser entrevistado explicó que:

"Yo no voy a renunciar a RN", dijo Horvath antes y después de la reunión con Matthei. "Yo no voy a renunciar a Renovación Nacional, me mantengo en contacto con la directiva, tengo afinidad con personas nuevas que veo hoy en día en el comando, como el caso de Karla Rubilar, con quien hemos trabajado hace muchos años, con Lily Pérez, con Pedro Browne, nosotros tenemos un ala más liberal, de centro en ese partido y eso tenemos que revitalizarlo", agregó ("Horvath no renuncia a RN y directiva busca evitar el 'síndrome Adolfo Zaldívar'", El Mostrador, 2013).

Si bien esa revitalización nunca se pudo llevar a cabo debido a las posteriores renuncias, el proyecto de materializarla sí confirma la escisión antes descrita.

Aquellos estudios que documentan la separación conservador-liberal en la década de los noventa (Aleuy y Arriagada, 2001; Godoy, 2005; Mackinnon, 2005) señalan un enfrentamiento permanente entre aquellos ligados al Régimen Militar de Augusto Pinochet y entre quienes eran partidarios de ampliar las libertades individuales y reforzar la democracia representativa. Dentro de Renovación Nacional, esto se tradujo en un distanciamiento entre los partidarios de Sergio Onofre Jarpa y los de Andrés Allamand. Este último, quien logró surgir como una entidad política en la primera década del retorno a la democracia, fue un fiel impulsor de la democracia de los acuerdos. También fomentó las negociaciones con la Concertación para eliminar las ataduras constitucionales impuestas por la dictadura (Allamand, 1999). Tal posición no solo generó intensos conflictos entre la UDI y RN, sino que provocó un gran remezón en el partido que culminó con la conducción de Allamand a la cabeza del partido.

Los cambios constitucionales serían postergados hasta el gobierno de Ricardo Lagos. En 2005, tras años de intensos debates e intercambios, la coalición gobernante y la oposición 
alcanzaron los consensos que hicieron posible modificar algunos aspectos de la carta fundamental como la eliminación de los senadores designados y la disminución de los periodos presidenciales. Una vez que se concretaron estas reformas, las diferencias ideológicas entre conservadores y liberales en RN alcanzaron un nuevo nivel: pasaron del ámbito político a cuestiones morales o valóricas. Uno de los senadores del partido se refirió de esta forma a polémicas que aún persisten: "Por un lado están todos los temas que dicen relación con familia. Incluso sobre el aborto hay diferencias. En proyectos de ley como el Acuerdo de Vida en Pareja. En relación a si aceptar o no el matrimonio igualitario. En su momento hubo incluso diferencias sobre si se aceptaba el divorcio o no". ${ }^{2}$

También en el plano legislativo, las mayores diferencias de la última década han estado en proyectos referentes al divorcio, al matrimonio o unión civil de parejas homosexuales, al aborto terapéutico y a la píldora del día después. En la votación referente a esta última en el 2009, Renovación Nacional fue el partido más dividido de todo el espectro político (tabla 1), con casi un tercio de sus diputados oponiéndose a la legislación que permitiría la distribución del fármaco contraceptivo. En el Senado, la votación de RN resultó igualmente contradictoria, con un empate de cuatro contra cuatro.

Tabla 1. Votación sobre la píldora del día después

\begin{tabular}{lccc}
\hline & $\begin{array}{c}\text { A favor } \\
\mathrm{n}(\%)\end{array}$ & $\begin{array}{c}\text { En contra } \\
\mathrm{n}(\%)\end{array}$ & $\begin{array}{c}\text { Abstenciones } \\
\mathrm{n}(\%)\end{array}$ \\
\hline RN & $11(69)$ & $5(31)$ & $0(0)$ \\
UDI & $5(15)$ & $26(81)$ & $1(1)$ \\
Concertación & $52(98)$ & $1(2)$ & $0(0)$ \\
\hline
\end{tabular}

Fuente: Elaboración propia a partir de información de la Cámara de Diputados de Chile.

Por su parte, los proyectos de Acuerdo de Vida en Pareja (AVP) y aborto terapéutico también enfrentaron internamente a miembros de Renovación Nacional. El AVP fue presentado por el gobierno de Piñera y promovido con fuerza por la senadora Lily Pérez. Sin embargo, fue rechazado por su timonel Carlos Larraín, quien argumentó que el proyecto se parecía demasiado al matrimonio homosexual ("Proyecto de ley de AVP genera nuevas tensiones en el oficialismo", La Segunda, 2013). En cuanto al aborto terapéutico, el consejo general realizó en septiembre de 2011 un voto político en su contra, lo que generó inmediatamente la molestia de la senadora Pérez y de la diputada Rubilar ("Aborto terapéutico desata encendido intercambio epistolar en RN", La Segunda, 2011).

Las divisiones dentro de Renovación Nacional en torno a temas valóricos adquirieron aún más relevancia en el periodo presidencial de Piñera. Pero ¿qué sucedió en materia de reformas políticas? Irónicamente, la crisis más águda fue provocada por la propia 
mesa directiva ("RN y DC presentaron propuesta conjunta de reforma al binominal"; La Tercera, 2012). Esta, comandada por Carlos Larraín, hizo un pacto secreto con la Democracia Cristiana para reformar el sistema binominal, el legado político restante más controversial del Régimen Militar. Mientras tanto, el gobierno de Piñera (uno de los pocos opositores a este en la derecha) se alineó con la UDI para bloquear dicho acuerdo. Ante los hechos, la UDI y parte de la bancada RN presentaron una propuesta alternativa ("Gobierno propone proyecto alternativo de reforma al sistema binominal", La Tercera, 2013). Fueron los parlamentarios liberales Alberto Espina y Lily Pérez quienes la respaldaron dentro del partido.

\section{DEMOCRACIA Y DEMOCRATIZACIÓN INTERNA}

Si bien Barozet y Aubry (2005), en su estudio acerca de la orgánica de Renovación Nacional, califican su democracia interna como pobre, sus militantes y políticos tienen una visión distinta en la actualidad. Luna y Rosenblatt (2012), en su análisis de las opiniones de parlamentarios de todos los partidos, encuentran una alta percepción de democracia interna en los de RN. Además, el respaldo a la institucionalidad democrática se manifestó en casi todas las entrevistas que sustentan este trabajo. Los opinantes además reconocen que si bien trae ciertas desventajas (hace más costosa la toma de decisiones), estas se justifican por el alto grado de legitimidad interna que otorga la democratización. Un diputado y miembro de la mesa directiva señala:

"La gracia de RN es que es un partido democrático. Excesivamente democrático, diría yo, pero eso lo hace más desordenado. Tiene ventajas y desventajas: en las organizaciones monolíticas donde se toman las decisiones entre 5 o 6, es más fácil que en las que se toman entre 200 mil o 15 mil. Nosotros hemos ido avanzando en profesionalizar nuestras normas internas y permitimos que cada militante tenga derecho a voto para elegir a todas las autoridades dentro del partido. [...] Nos facilita la vida porque tú te sacas de responsabilidad, como directiva o como dirigente, de escoger entre dos o tres gallos muy buenos. Mejor que lo decida la gente" ${ }^{3}$

Esta característica es un componente sólido de la identidad del partido y un rasgo diferenciador de la UDI, que es visto como monolítica y cerrada. Otro de los militantes lo expresó de esta forma: "Renovación Nacional frente a la UDI está a años luz de participación y de democracia interna". ${ }^{4}$

Hay tres factores clave que contribuyen a aumentar la democracia dentro de RN. En primer lugar, la mesa directiva es elegida por los militantes en elecciones directas y competitivas ("Las gestiones de la oposición a Larraín y de Allamand en medio del conflicto de RN", La Tercera, 2011). En ellas impera la lógica de un militante un voto, que también se aplica en la elección de las directivas y consejeros distritales y regionales. Los miembros del consejo general, compuesto por la totalidad de los consejeros generales, 
son a su vez consejeros distritales y regionales en sus zonas. En consecuencia, ningún miembro del consejo general ha sido designado sin un proceso democrático.

Finalmente, la incidencia real que tiene el consejo general en la toma de decisiones termina de legitimarlo como un mecanismo democrático. La exhibición más clara de lo anterior se vio en el consejo general del 2005, previo a la campaña presidencial (Allamand y Cubillos, 2010). Entonces, Joaquín Lavín se perfilaba como el candidato único de la derecha para desafiar a la Concertación luego de casi derrotar a Ricardo Lagos en la elección anterior. Si bien la directiva ya lo había ratificado, este debía ser proclamado por el consejo general. Tras una intensa discusión, el órgano optó por proclamar a su anterior líder, Sebastián Piñera.

Aunque la totalidad de los entrevistados se mostraron satisfechos con la existencia de estos mecanismos, también existieron reparos:

"La democracia no solamente tiene que ver con cómo se elige un gobernante, sino con cómo se ejerce su democracia. [...] Si bien en RN hay democracia interna formal, muchas de las decisiones se toman de forma cupular. [...] En decisiones clave como apoyar a [la candidatura senatorial del ex-ministro] Cruz-Coke y no [al incumbente] Cantero. El que Carlos Larraín haya asumido la senatorial en vez del diputado nuestro. Esas fueron medidas que tomaron las directivas en 15 minutos". ${ }^{5}$

La literatura politológica ha definido la democracia interna de los partidos considerando múltiples factores. Freidenberg $(2003 ; 2006)$ en su investigación exhaustiva de los progresivos cambios y demandas por mayor democracia en estas organizaciones en América Latina, define tres elementos necesarios pero no suficientes: la rendición de cuentas de los cargos públicos y autoridades; la inclusión de minorías (mujeres, pueblos originarios, etc.); y la selección abierta de candidatos a cargos de representación política (en contraposición a mecanismos cupulares donde las élites tienen todo el poder para designarlos).

En el caso chileno, estas dimensiones han sido analizadas por Arce (2013), quien sostiene que con una deficiente legislación de partidos, el país muestra un sistema sumamente desregulado en su funcionamiento y en su financiamiento. La inclusión de minorías, por su parte, no está contemplada ni por la legislación actual ni por estas entidades. Específicamente en $\mathrm{RN}$ se observan irregularidades en el proceso eleccionario y un estricto control de la selección de candidatos por parte de las cúpulas partidistas. Al respecto, Arce señala (pp. 93):

"En el caso de RN, la situación no ha sido diferente, en un proceso electoral se detectó el procedimiento de 'urna móvil', al momento de realizar la elección a causa de la escasa presencia de votantes. Esto consiste en que la urna se sube al interior de un vehículo y, padrón electoral en mano, se decide pasar por cada una de las casas de los militantes de la comuna". 
En cuanto a la rendición de cuentas, los entrevistados confirman que la mesa directiva tiene una alta capacidad para tomar decisiones sin responderle a los militantes. La prevalencia de resoluciones centralizadas es admitida incluso por un miembro de la actual mesa directiva: "En RN siempre ha habido una profundización y un número importante de decisiones que se toman en regiones. Entendiendo que siempre se corta el queque en Santiago cuando llega más de un nombre propuesto. Aunque eso se vio limitado por el proceso de primarias" ${ }^{6}{ }^{6}$

La selección de candidatos a cargos de representación (parlamentarios, alcaldes, etc.) es otra área de incertidumbre esencial para entender cómo se ejerce el poder dentro de un partido político. Katz (2001) argumenta que esta dimensión ocupa un rol central por múltiples razones: los candidatos son el rostro público al verse expuestos a la competencia electoral; la selección constituye un proceso de reclutamiento en el que ciertos miembros adquieren un estatus especial; estos muchas veces representan a sectores descentralizados (comunidades locales) que no siempre están dentro de las élites partidistas; y finalmente, la selección es una negociación partidaria y una exposición del poder relativo de los grupos internos, donde el que alcanza mayor cantidad y calidad de candidaturas logrará un mayor posicionamiento dentro del partido. De esta forma, si una facción desafiante logra situar un número importante de candidatos parlamentarios, esto constituirá una amenaza a la hegemonía de aquella dominante, aumentando los incentivos para incluir a los primeros.

Durante el proceso de entrevistas lo que generó mayores cuestionamientos a la democracia interna fue la selección de candidatos:

"Hay un organismo que se llama el comité electoral, que es el que finalmente elige a esos candidatos, que los designa, y la nominación al final es aprobada o rechazada por el consejo general. Pero el problema está en quienes componen este comité. No hay un proceso serio que avale dicha selección. No hay un mecanismo bien claro y transparente. [...] Finalmente se convierte en un juego de negociación, de poder, de facciones dentro del partido, que finalmente determina si llevamos a uno de candidato o si llevamos al otro". ${ }^{7}$

Si bien formalmente los candidatos son electos por los miembros de sus distritos, la decisión final debe pasar por la mesa central del partido. Juega un rol especialmente importante el comité electoral de RN, que a diferencia de otros órganos como el consejo general o la mesa directiva, cuenta con miembros que no son electos democráticamente, sino que son designados informalmente por la mesa directiva, por las distintas bancadas parlamentarias y por los caudillos con influencia.

Algunos miembros de la colectividad cuestionan bastante el poder ejercido por el expresidente de la mesa directiva, Carlos Larraín, quien ostentó desde 2006 hasta 2014, y que fue criticado tanto por su estilo jerárquico como por el poder informal que ejerció al ser uno de los principales sostenedores económicos del partido y de sus candidatos: 
"[En la lista alternativa iba] a haber un nuevo estilo, una nueva conducción del partido. Era cambiar un poco la conducción quizás un poco agresiva o de patrón que tiene don Carlos". 8

"Él es un conservador, es muy patrón de fundo. Cosa que no me gusta y se lo he dicho en la cara. [...] Larraín es así, tú te fuiste en contra y te va a hacer la vida 'a cuadritos' hasta que te mueras. Nunca voy a estar de acuerdo con esa forma. Yo lo he visto, no es que me lo hayan contado. He visto cómo han sufrido dirigentes por estar en desacuerdo con él". ${ }^{9}$

"El gran sustento monetario del partido es Carlos Larraín y un par de personas más". 10

Algunos de los entrevistados, al referirse a este punto, mencionaron el caso de "RN Bicentenario", un grupo encabezado por Cristián Monckeberg que en 2010 se opuso a Larraín, y que fue calificado por la prensa como el producto de una disputa entre liberales y conservadores ("Liberales y conservadores se enfrentan en internas del partido de Piñera", Qué Pasa, 2010). En dicho momento, Monckeberg, conservador moderado ligado al Opus Dei, contrario al proyecto de píldora del día después, conformó una lista con miembros del ala liberal como la diputada Karla Rubilar.

Uno de los entrevistados llegó a señalar que "Informalmente, ha habido diferencias ideológicas pero yo no me atrevería a clasificarlas como más conservador o más liberal. Por eso me da risa cuando dicen que Cristián Monckeberg o Nicolás Monckeberg representan al ala liberal de Renovación, porque no son para nada liberales" ${ }^{11}$ En esa oportunidad, Larraín comentó el episodio ("Carlos Larraín fustigó a Cristián Monckeberg por sus posturas valóricas", Cooperativa , 2010), señalando que no respondía tanto a una división conservador-liberal como a un estilo de conducción:

"Yo creo que es una cosa mucho más sencilla y menos dramática, es simplemente que se mantenga una línea de trabajo como el que nosotros llevamos en la directiva que yo presido o apostar por una tesis nueva que todavía no se alcanza a identificar muy bien, eso es todo".

Monckeberg terminaría en la presidencia del partido en 2014 luego de dirigir una lista de unidad en las elecciones. ¿Pero cuáles eran las diferencias de estilo entre las dos candidaturas a la mesa directiva en esa oportunidad? Al respecto, el abogado y asesor legislativo Roberto Munita sostiene que la respuesta está en la apertura de la cultura organizativa, con la mesa opositora alejándose del estilo de Larraín y buscando suplir las falencias de democracia interna:

"Si yo lo tuviera que dividir un poco la ideología entre esta lista paralela y el mainstream (Carlos Larraín y su gente) es una visión verticalista frente a una horizontalista de

Entrevista con un militante de Renovación Nacional, Santiago, Santiago, octubre 2013.

Entrevista con una consejera general de Renovación Nacional, Valparaíso, octubre 2013.

Entrevista con un consejero general de Renovación Nacional, Santiago, noviembre 2013

Entrevista con un militante de Renovación Nacional, Santiago, septiembre 2013. 
hacer política. Larraín, Ossandón y toda esta gente tienen una visión vertical, de patrón de fundo. Me refiero a que uno anda y otro obedece" ${ }^{\prime 12}$

A juicio de Munita, esta división entre horizontalistas y verticalistas se extiende más allá de las elecciones internas del 2010 y responde a diferencias generacionales y de cultura política.

"Hay una cuestión generacional, es más probable que los gallos más jóvenes sean más bien de esta onda más horizontal, porque nosotros hemos sido criados así. [...] Las generaciones jóvenes que han ingresado a RN lo han hecho con esta lógica mucho más horizontal. Muchas veces molesta que la palabra de un caballero que dirige el partido sea ley. [...] A esto me refiero con que sean más horizontales: buscan acuerdos, saben que hay que darle importancia a instituciones como la comisión política (que creo que eso es el meollo de la decisión colectiva). En cambio los verticalistas son partidarios de darle menos importancia a la comisión política". ${ }^{13}$

\section{DE OPOSICIÓN A OFICIALISMO}

Si bien una vez terminado el periodo de Piñera, los partidos del sector defendieron acérrimamente su legado, durante su estadía en La Moneda se generaron polémicas entre ellos de forma recurrente. Esta administración fue presa de constantes conflictos con la UDI (por ejemplo, por sus críticas hacia el rol de la derecha en el Gobierno Militar, "UDI realiza velada crítica a Presidente Piñera por clima previo a muerte de Mena", El Mostrador, 2013), pero también con RN. Es más, sus representantes han expresado en distintas ocasiones su decepción ante la aparente preferencia de Piñera por la UDI ("Las pasadas de factura que se alistan en la derecha para después de la elección", El Mostrador, 2013):

Según explican en RN, "la UDI no debería tener de qué quejarse en esta elección, porque su apoyo a Piñera ha sido ampliamente recompensado, no así la lealtad de RN, donde muchas veces nos hemos tenido que morder la lengua para no perjudicarlo". Un consejero va más allá, señalando que "Piñera le tiene tanto miedo a la UDI que cada vez que ha presionado, él le da lo que pide. Así cualquiera es leal".

Todos los entrevistados, tanto liberales como conservadores, ven con ojos sumamente positivos el desempeño del gobierno de Piñera en cuanto a políticas públicas. No así con la relación que ha entablado con el partido, siendo usuales las quejas por la poca designación de sus militantes a los puestos gubernamentales.

"Yo tengo cifras de cuántas personas se fueron [del gobierno local de una de las regiones], y son muchos más durante las administraciones de la Concertación que con Sebastián Piñera. Entonces eso nos ha generado insatisfacción dentro del partido, 
de gente que dice 'ya llevamos 3 años de gobierno y no he podido llegar a ninguna pega, a ninguna intendencia...', por eso hemos tenido una crítica bastante grande". ${ }^{14}$

"Creo que como Renovación Nacional no estábamos preparados. Nunca pensamos en lo que podía pasar. No estábamos listos. Ganamos todo, llegamos a La Moneda, traigan los currículum, a quiénes dejamos aquí, a quiénes dejamos allá. Nosotros no teníamos nada. Y la UDI con sus notebook y vamos. 'Para este cargo tengo a este tipo'. Nosotros no teníamos nada". 15

Las diferencias entre el partido y el gobierno también tuvieron una importante presencia en los medios. Miembros de la mesa directiva polemizaron constantemente con el Ejecutivo (especialmente con la figura de Piñera) y viceversa ("Piñera dispara contra Carlos Larraín y dice que sus últimas declaraciones 'no aportan en nada'", El Mostrador, 2013; “Ossandón critica a Piñera por socializar su fundación a solo días de las elecciones", La Tercera, 2013).

Tanto en el proceso de entrevistas como en las declaraciones de prensa, los reproches hacia Piñera se explican no por diferencias ideológicas sino por la deficiente relación entre el partido y el gobierno, que se tradujo en una lucha caudillista que separó a quienes seguían a Piñera de quienes a Larraín. Un consejero general lo expresa de esta manera:

"Soy de la facción más liberal de Renovación Nacional, pero circunstancialmente voy a estar del lado de Carlos Larraín, no del de Sebastián Piñera. Es raro, es muy raro. [...] Mucha gente se sintió desplazada porque no éramos escuchados por el gobierno. También muchos dirigentes se dejan llevar por liderazgos. Hay mucha gente que no adopta posturas de acuerdo al eje conservador-liberal sino mucho más por el caudillismo". ${ }^{16}$

Las tendencias que alberga RN no han logrado constituirse como facciones estables a lo largo del tiempo, lo que es reconocido por otro de los entrevistados al señalar que: "No hay facciones estables a lo largo del tiempo. En los 90 era quienes seguían a Jarpa, más algunos UDI estancados en el partido y aquellos que seguían a Allamand. Pero va variando, va cambiando. Las facciones varían, evolucionan, cambian, por temas estratégicos, ideológicos o contingentes. No sé, pero varían". ${ }^{17}$ De hecho, el último año del gobierno de Sebastián Piñera vio la consolidación clara de un grupo de militantes cercanos a él, al punto de que "piñerismo" se volvió un término recurrente en la prensa ("Matthei alista estrategia de campaña con énfasis en la "nueva derecha"", La Tercera, 2013).

El momento cúlmine de este proceso fue la renuncia de Daniel Platovsky, uno de sus miembros históricos, y su anuncio de creación de un nuevo referente piñerista ya sea dentro o fuera de Renovación Nacional. En esa oportunidad, el reportaje donde se anunciaba la noticia ("Renuncia de Platovsky a RN reaviva discusión por nuevo

Entrevista a un senador de Renovación Nacional, Santiago, septiembre 2013.

Entrevista con un miembro de la mesa directiva de Renovación Nacional, Santiago, septiembre 2013.

Entrevista con un consejero general de Renovación Nacional, Santiago, noviembre 2013.

Entrevista con una consejera general de Renovación Nacional, Valparaíso, octubre 2013. 
referente 'piñerista'", La Segunda, 2013), afirmaba la importancia de medir las fuerzas de los cercanos a Larraín en las siguientes elecciones:

El factor clave para decidir, dicen algunos en la disidencia, va a estar en la elección senatorial de Santiago Poniente y en el resultado electoral de los cercanos al timonel Carlos Larraín. En caso de que Andrés Allamand pierda frente al UDI Pablo Zalaquett, y que dicho resultado electoral sea malo, regresaría Platovsky y el "piñerismo" trataría de retomar la conducción del partido. Ello, con dirigentes como los actuales ministros Rodrigo Hinzpeter o Cecilia Pérez, más Alberto Espina.

Y si bien los periodistas rápidamente definieron a este nuevo grupo como la escisión de los liberales del partido, las mismas fuentes internas aclararon que se trataba de dimensiones distintas:

En medio de la discusión, se aclara en fuentes de RN que el grupo que podría partir de la colectividad, en caso de concretarse lo del nuevo referente, no es uniforme. Se señala que no hay que confundir la disidencia a Larraín o a los liberales con el "piñerismo".

Ninguna de las entrevistas realizadas con posterioridad a la renuncia de Platovsky enmarcó el conflicto en un plano ideológico. En una de ellas, realizada a un consejero general, se explica este hecho como un rechazo al timonel al sostener que "La renuncia de Daniel hace referencia a la presencia de Larraín. Si me preguntas a mí, radica más en eso que en el tema de si estamos de acuerdo o no con Piñera. [...] Pero la forma de hacer política que ha demostrado Larraín es la que a muchos no nos gusta". ${ }^{18}$ Sin embargo, otro de estos consejeros lo define como la representación de una visión a favor de la administración del Presidente de la República:

“Hoy día la facción más pro-gobierno, pro-Sebastián Piñera está representada principalmente por Rodrigo Hinzpeter, por Rodrigo Ubilla, por Lily Pérez, por Alberto Espina. [...] Por el otro lado está Carlos Larraín, el Coté Ossandón, Francisco Chahuán, Mario Desbordes, diputados como Alberto Cardemil, etc. Esas son las figuras, pero al final lo que importa es cómo están tus redes abajo. Hoy estaba leyendo un reportaje, y me surgió la duda de si para las próximas internas esta división se va a concretar, sobre todo tras la renuncia de Daniel Platovsky. Si va a haber un enfrentamiento entre las dos visiones". ${ }^{19}$

Uno de los entrevistados interpreta incluso la candidatura de Cristián Monckeberg a la mesa directiva bajo "RN Bicentenario" en 2010 como un conflicto entre el gobierno y el partido, cuya victoria implicaría "En términos prácticos no mucho, si lo único que servía era para que La Moneda no tuviera problemas notorios con la mesa directiva" ${ }^{20}$ La llegada de $\mathrm{RN}$ al gobierno ha significado un nuevo y notorio eje de división en su interior, con claras figuras cercanas a este y otras alineadas a la mesa directiva. 


\section{REPLANTEANDO DIVISIONES PARTIDARIAS}

Las tres dimensiones desarrolladas en las secciones anteriores permiten una visualización más completa de las divisiones partidarias en Renovación Nacional, y al graficarlas de forma tridimensional (Figura 2), podemos posicionar a sus distintos políticos y sectores.

Es posible diferenciar entre quienes son más conservadores o liberales en el área valórica, entre quienes tienen una visión más vertical u horizontal en la conducción del partido, y entre quienes son más partidarios del gobierno versus los cercanos a la mesa directiva. La diputada Karla Rubilar, por ejemplo, se reveló durante el periodo presidencial de Piñera como una figura marcadamente liberal, horizontalista y con tendencia a polemizar con la mesa directiva, en una posición similar a la que ocupa la senadora Lily Pérez, otra gran defensora del legado del gobierno. En el lado diametralmente opuesto se ubica el expresidente del partido Carlos Larraín, reconocido conservador y verticalista y junto a él, el vicepresidente del partido y exalcalde de Puente Alto, Manuel José Ossandón.

Dos aclaraciones son necesarias. En primer lugar, no todos los ejes son estrictamente relevantes para cada miembro del partido en cada momento y en cada conflicto. La coyuntura respecto de la agenda de matrimonio igualitario, por ejemplo, podría

Figura 2. Nuevos ejes de división dentro de Renovación Nacional

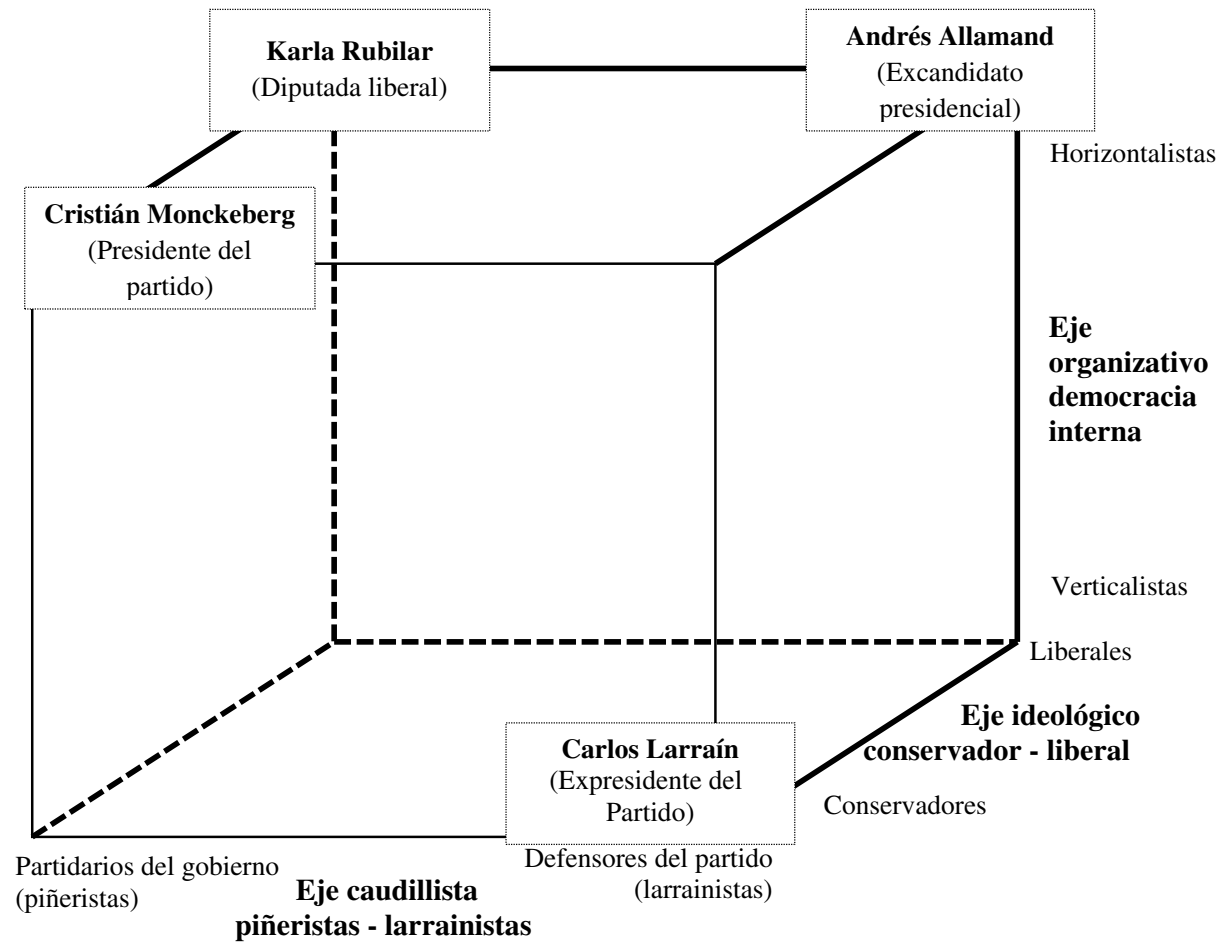

Fuente: Elaboración propia. 
poner de relieve las diferencias en torno a las cuestiones valóricas, pero puede que ciertos diputados no tengan gran interés en esta temática y que su posición sea de baja intensidad. En segundo lugar, hay un cierto grado de sobreposición esperada entre los distintos ejes. A primera vista, los partidarios del piñerismo parecen sostener posiciones más liberales que los partidarios de la mesa presidida por Larraín. Sin embargo, los ejes son independientes entre sí. Diputados como Nicolás y Cristián Monckeberg sostienen posiciones conservadoras, pero apoyan una conducción más abierta y son percibidos como cercanos al gobierno. Por otro lado, Andrés Allamand, el principal expositor del liberalismo histórico, tiende a ubicarse cercano a Carlos Larraín por motivos caudillistas y circunstanciales, pese a haber sido ministro de Piñera.

Con lo anterior dicho, este nuevo esquema permite comprender algunas de las paradojas antes observadas en materia de conflictos internos. Situar todas las diferencias en el marco del eje conservador-liberal conduce a lecturas equivocadas. Podemos generar explicaciones alternativas de mayor precisión a partir de este esquema tridimensional.

El acuerdo suscrito entre Renovación Nacional y la Democracia Cristiana para cambiar el sistema binominal es el ejemplo más nítido de aquello. El sistema electoral representaba el último gran enclave autoritario restante de la dictadura, y su importancia radica en que determina la distribución de poder en el sistema político y en la conformación del sistema de partidos. En los años 90, fueron los liberales de RN (liderados por Allamand) quienes estuvieron dispuestos a negociar con la Concertación para acabar con los enclaves autoritarios, pero se vieron frustrados por el ala conservadora que se mostró más reacia. Los grandes cambios constitucionales se dieron -con el apoyo de todos los partidosen el periodo presidencial de Ricardo Lagos, pero el binominal permaneció intacto.

A la mitad del gobierno de Piñera, el sistema electoral volvió al centro de la polémica al gestarse el acuerdo entre RN y la DC para reformarlo, sin el conocimiento del Ejecutivo ni de la UDI, quienes se encontraron desprevenidos e incómodos ante la situación. Sin embargo, quienes lideraron el trato no fueron los sectores liberales, que no ostentaban el poder en ese entonces, sino la mesa directiva de tendencia conservadora. Más aún, fueron parlamentarios reconocidos en la prensa como liberales los que se opusieron a este.

¿Qué explica este constante intercambio de roles frente a las propuestas políticas de los 90 ? Por un lado, que las diferencias entre las denominadas alas conservadoras y liberales pasaron de tener una naturaleza política a una moralista. Pero para ser más precisos, esta división no fue un factor tan relevante como las divergencias de la mesa directiva (y el sector que la apoyaba) con el manejo político del gobierno. Militantes que acusaban un favoritismo por la UDI lograron aislar a esta y complicar la posición comunicacional de La Moneda. Esta jugada, además, evidenció una contradicción entre la forma en que el gobierno y el partido estaban siendo conducidos.

Por otra parte, este nuevo esquema nos ayuda a comprender la escisión de parlamentarios del partido en las primeras semanas de 2014 para formar Amplitud. En esta oportunidad, los diputados Joaquín Godoy, Karla Rubilar y Pedro Brown -a los que más tarde se les sumaría la senadora Lily Pérez-, romperían con el partido para impulsar su propio movimiento de orientación de centro-derecha. 
Si bien los parlamentarios que lo integraron encajaban con el perfil de "los liberales" de $\mathrm{RN}$, el quiebre hizo visibles elementos de todos los niveles de división partidaria definidos anteriormente.

En las declaraciones y documentos emitidos al momento del conflicto, los integrantes de Amplitud enumeraron como causas del quiebre tanto el marcado carácter ideológico como los procesos de deliberación interna. "Para nosotros, Renovación Nacional es hoy un partido conservador donde las diferencias no son respetadas" ("Karla Rubilar, Joaquín Godoy y Pedro Browne confirman renuncia a Renovación Nacional", La Tercera, 2014). Lily Pérez también apuntó a factores institucionales previo a su renuncia, al señalar que era necesario que "hubiera una verdadera renovación en todo lo que es el concepto estructural del partido".

Sin embargo, también es posible clasificar a los miembros de este nuevo referente dentro del eje caudillista que enfrenta a la mesa directiva y el gobierno. En esta dimensión, Pérez marcó una posición antagónica a la de la mesa al señalar que: “creo que la mesa directiva está absolutamente agotada y que deberían dar un paso al costado pero que debiera ser algo de ellos, voluntario". La senadora realizó simultáneamente una defensa al gobierno de Piñera y una crítica al manejo de la mesa, tal como apunta La Tercera:

En cuanto a Sebastián Piñera y su rol como Presidente, la senadora dijo que "este es un Gobierno que ha estado expuesto permanentemente al ataque" y que a la directiva de RN le faltó "reconocer que este ha sido un buen Gobierno y como todo buen Gobierno, hay cosas que se pudieron haber hecho mejor" ("Lily Pérez: 'La mesa directiva de RN está absolutamente agotada y debería dar un paso al costado'", La Tercera, 2014).

\section{CONCLUSIONES}

La investigación presentada aquí busca identificar con mayor precisión las divisiones de Renovación Nacional y hacer visible que sus dinámicas internas son más complejas que lo usualmente descrito por la literatura existente. Si bien el esquema tridimensional presentado ayuda a comprender los conflictos a lo largo del periodo de Piñera y muestra un partido con tendencia a la inestabilidad y a la fragmentación, esto no implica que estas categorías se mantengan en próximos periodos políticos. Los ejes de división se transforman con el tiempo (como el conservador-liberal), aparecen o desaparecen (como sucedió con las desaveniencias originadas con la llegada al gobierno), y están marcados tanto por criterios ideológicos como caudillistas (el polémico estilo de su presidente, Carlos Larraín, por ejemplo).

Uno de los principales hallazgos de este artículo es que una vez que Renovación Nacional llegó a La Moneda, tres ejes de división interna salieron a la superficie. Una de las preguntas insoslayables es de qué forma las características de RN (en particular, su escasa institucionalización y la presencia de caudillismo) propiciaron la existencia de estos conflictos. ¿Una estructura de toma de decisiones estable y democrática habría contribuido a aminorarlos? 
Los partidos con pobre institucionalización y que tienden al caudillismo descansan por definición en una o varias figuras emblemáticas. Una vez que estos llegan al poder, necesariamente debe producirse una reorganización de sus caudillos. En una futura línea de investigación sería interesante analizar para los países Latinoamericanos, a nivel empírico, en qué circunstancias y qué consecuencias tiene para la organización interna de los partidos caudillistas su llegada al poder.

La baja democratización interna es un problema endémico de los partidos chilenos y en RN se agudiza debido a sus mecanismos descentralizados y abiertos. No obstante, una democracia interna sólida requiere la apertura no solo de mecanismos formales sino de otros elementos y prácticas informales. Katz (2001) describe cómo los partidos y las facciones cartelísticas (aquellas que buscan perpetuarse en el poder para su propio beneficio) descentralizan y democratizan sus prácticas para diluir las resistencias internas, e imposibilitar el surgimiento de liderazgos alternativos. La reciente legislación nacional respecto de primarias internas permitirá examinar cómo y hasta qué punto las élites de Renovación Nacional estarán dispuestas a ceder control a cambio de legitimidad.

\section{REFERENCIAS}

Aleuy, Mahmud y Arriagada, Genaro. 2001. “Renovación Nacional: La Claudicación de los Liberales". Política Nacional 16.

Allamand, Andrés. 1999. La travesía del desierto. Santiago: Aguilar.

Allamand, Andrés y Cubillos, Marcela. 2010. La Estrella y el Arco Iris. Santiago: Aguilar.

Arce, Javiera. 2013. “Dilemas de la democracia interna de los partidos políticos en Chile: ¿Cómo participan los jóvenes militantes?". Andamios 8: 86-102.

Barozet, Emmanuelle y Aubry, Marcel. 2005. “De las reformas internas a la candidatura presidencial autónoma: los nuevos caminos institucionales de Renovación Nacional". Política 45: 165-196.

Cámara de Diputados (n.d.). Boletín Nº 6582-11.

Freidenberg, Flavia. 2003. Selección de candidatos y democracia interna en los partidos de América Latina. Lima: Asociación Civil Transparencia.

Freidenberg, Flavia. 2006. "La democratización de los partidos políticos: entre la ilusión y el desencanto". En Fortalecimiento de los partidos políticos en América Latina: institucionalización, democratización y transparencia, editado por José Thompson y Fernando Sánchez. San José de Costa Rica: Instituto Interamericano de Derechos Humanos, 91-140.

Garretón, Manuel Antonio. 2003. Incomplete Democracy. Chapel Hill: University of North Carolina Press.

Gibson, Edward. 2003. "Conservative electoral movements and democratic politics: core constituencies, coalition building, and the Latin American electoral Right". En The Right and Democracy in Latin America, editado por Douglas Chalmers, Maria do Carmo Campello de Souza y Atilio Boron. Praeger, 13-42.

Godoy, Oscar. 2005. "Horizontes futuros de la derecha chilena". Política 45: 207-214.

Hinojosa, Magda. 2009. “'Whatever the Party Asks of Me': Women's Political Representation in Chile's Unión Demócrata Independiente". Politics \& Gender 5 (3): 377-407.

Huneeus, Carlos. 2001. La derecha en el Chile después de Pinochet: el caso de la Unión Demócrata Independiente. Helen Kellogg Institute for International Studies.

Katz, Richard. 2001. "The problem of candidate selection and models of party democracy". Party Politics 7 (3): 277-296.

Kitschelt, Herbert. 1994. The transformation of European social democracy. Cambridge: Cambridge University Press.

Klein, Markus. 2004. “The Unión Demócrata Independiente and the Poor (1983-1992): The Survival of Clientelistic Traditions in Chilean Politics". Jahrbuch fur Geschichte Lateinamerikas 41: 301-324. 
Levitsky, Steven. 2003. Transforming labor-based parties in Latin America: Argentine Peronism in comparative perspective. Cambridge: Cambridge University Press.

Levitsky, Steven y Roberts, Kenneth (eds.). 2013. The resurgence of the Latin American left. Johns Hopkins University Press.

Luna, Juan Pablo. (2010). "Segmented Party-Voter Linkages in Latin America: The Case of the UDI". Journal of Latin American Studies 42 (2): 325-356.

Luna, Juan Pablo y Kaltwasser, Cristobal Rovira. 2011. "Las derechas gobernantes en América Latina: hacia una caracterización preliminar". LASA Forum 13 (3): 16-19.

Luna, Juan Pablo y Kaltwasser, Cristobal Rovira (eds.). 2014. The Resilience of the Latin American Right. Johns Hopkins University Press.

Luna, Juan Pablo y Rosenblatt, Fernando. 2012. “¿Notas para una autopsia? Los partidos políticos en el Chile actual". En Democracia con partidos. Informe para la reforma de los partidos politicos en Chile (115252), editado por Francisco Javier Díaz y Lucas Sierra. Santiago: CEP, Cieplan.

Mackinnon, Ian. 2005. "Renovación Nacional: entre conservadores y reformistas". Tesis de Licenciatura en Ciencia Política. Santiago: Instituto de Ciencia Política, Universidad Católica de Chile, 2005.

Morales, Mauricio y Bugueño, Rodrigo. 2001. "La UDI como expresión de la nueva derecha en Chile". Estudios Sociales 7: 2-26.

Panebianco, Ángelo. 1990. Modelos de partido: organización y poder en los partidos políticos. Madrid: Alianza editorial.

Renovación Nacional (n.d.). Estatuto de Renovación Nacional.

Roberts, Kenneth. 2014. "Democracy, Free Markets and the Rightist Dilemma in Latin America". En The Resilience of the Latin American Right, editado por Juan Pablo Luna y Cristobal Kaltwasser. Johns Hopkins University Press, 25-47.

Sáez, Manuel Alcántara. 2004. "Partidos políticos en América Latina: precisiones conceptuales, estado actual y retos futuros". Documentos CIDOB. América Latina 3 (1).

Siavelis, Peter. 2014. "The Right's Evolution from Demoracy to Authoritarianism and Back Again". En The Resilience of the Latin American Right, editado por Juan Pablo Luna y Cristobal Kaltwasser. Johns Hopkins University Press, 242-267.

Soto, Ángel. 2001. "La irrupción de la UDI en las poblaciones 1983-1987”. En Trabajo preparado para ser presentado en la reunión anual de la LASA (Latin American Studies Association), Washington DC, septiembre, 6-8.

Wiesehomeier, Nina. \& Doyle, David. 2014. "Profiling the Electorate Ideology and Attitude of Rightwing Voters". En The Resilience of the Latin American Right, editado por Juan Pablo Luna y Cristobal Kaltwasser. Johns Hopkins University Press, 48-72.

\section{Prensa}

Araya, E. y Hernández N. 2012. "RN y DC presentaron propuesta conjunta de reforma al binominal". La Tercera (18 de enero).

Cooperativa.cl. 2010. "Carlos Larraín fustigó a Cristián Monckeberg por sus posturas valóricas". Cooperativa (11 de junio).

Contreras, M. (2013). "Renuncia de Platovsky a RN reaviva discusión por nuevo referente 'piñerista'". La Segunda (15 de octubre).

EFE. 2010. “Liberales y conservadores se enfrentan en internas del partido de Piñera. Qué!" (11 de junio).

El Mostrador/UPI. 2013. "Piñera dispara contra Carlos Larraín y dice que sus últimas declaraciones 'no aportan en nada'". El Mostrador (12 de noviembre).

Jiménez, M. 2013. "Horvath no renuncia a RN y directiva busca evitar el 'síndrome Adolfo Zaldívar'". El Mostrador (22 de noviembre).

La Segunda. 2011. "Aborto terapéutico desata encendido intercambio epistolar en RN". La Segunda (14 de septiembre).

La Segunda. 2013. "Proyecto de ley de AVP genera nuevas tensiones en el oficialismo". La Segunda (4 de diciembre). 
La Tercera. 2013. "Ossandón critica a Piñera por socializar su fundación a solo días de las elecciones". La Tercera (13 de diciembre).

Mascareño, C. 2014. “Lily Pérez: 'La mesa directiva de RN está absolutamente agotada y debería dar un paso al costado'". La Tercera (7 de enero).

Pavéz, M. y Toro P. 2011. "Las gestiones de la oposición a Larraín y de Allamand en medio del conflicto de $\mathrm{RN}^{\prime \prime}$. La Tercera (20 de noviembre).

Rivas, C. 2013. "Las pasadas de factura que se alistan en la derecha para después de la elección". El Mostrador (15 de noviembre).

Toro, P. 2013. "Matthei alista estrategia de campaña con énfasis en la 'nueva derecha'”. La Tercera (18 de octubre).

Torrealba, F. 2013. “Andrés Allamand: 'El principal responsable del fracaso electoral es Piñera'". La Tercera (21 de diciembre).

Torrealba, F. y Labra, A. 2014. "Karla Rubilar, Joaquín Godoy y Pedro Browne confirman renuncia a Renovación Nacional". La Tercera (7 de enero).

Wilson, J.M. y Labra, A. 2013. "Gobierno propone proyecto alternativo de reforma al sistema binominal". La Tercera (11 de julio).

Nicolás Díaz es licenciado en ciencias sociales y bachiller en ciencias sociales y humanidades en la Pontificia Universidad Católica de Chile. Es coeditor del libro ¿Democracia Universitaria? Un aporte a la discusión en la Pontificia Universidad Católica de Chile. E-mail: nsdiaz@uc.cl. 